\title{
Inside-out and standard vein grafts associated with platelet-rich plasma (PRP) in sciatic nerve repair. A histomorphometric study ${ }^{1}$
}

José Sidney Roque', Karina Torres Pomini", Rogério Leone Buchaim"I', Daniela Vieira Buchaimv, Jesus Carlos Andreov, Domingos Donizeti Roquev ${ }^{v 1}$, Antonio de Castro Rodriguesv, Geraldo Marco Rosa Júnior $^{\mathrm{VII}}$, Luis Henrique Rapucci Moraes ${ }^{\mathrm{VIII}}$, Fausto Viterbo ${ }^{\mathrm{IX}}$

'PhD, Department of Anatomy, Universidade Estadual do Norte do Paraná (UENP), Jacarezinho-PR, Brazil. Acquisition, analysis and interpretation of data; technical procedures.

"MSc, Department of Biological Sciences, Faculdade de Odontologia de Bauru, Universidade de São Paulo (FOB-USP), Bauru-SP, Brazil. Manuscript preparation and writing.

I'PhD, Department of Biological Sciences, FOB-USP, Bauru-SP, Brazil. Conception and design of the study, critical revision, final approval.

IVPhD, Division of Human Morphophysiology, Medical School, Universidade de Marilia (UNIMAR), Brazil. Conception and design of the study, critical revision, final approval.

${ }^{V}$ PhD, Department of Biological Sciences, FOB-USP, Bauru-SP, Brazil. Scientific and intellectual content of the study.

VIPhD, Division of Human Morphophysiology, Medical School, UNIMAR, Marilia-SP, Brazil. Acquisition, analysis and interpretation of data.

VIIPhD, Health Sciences Center, Universidade do Sagrado Coração (USC), Bauru-SP, Brazil. Technical procedures, histopathological examinations, statistical analysis.

VIIIPhD, Department of Structural and Functional Biology, Institute of Biology, Universidade Estadual de Campinas (UNICAMP), Brazil. Technical procedures, histopathological examinations, statistical analysis.

IXPhD, Division of Plastic Surgery, Department of Surgery and Orthopedics, Universidade Estadual Paulista Julio de Mesquita Filho (UNESP), Botucatu-SP, Brazil. Scientific and intellectual content of the study.

\section{Abstract}

Purpose: To evaluated the tubulization technique with standard and inside-out vein, filled or not with platelet-rich plasma (PRP), in sciatic nerve repair.

Methods: Seventy male Wistar rats were randomly divided into five groups: IOVNF (InsideOut Vein with No Filling); IOVPRP (Inside-Out Vein filled with PRP); SVNF (Standard Vein with No Filling); SVPRP (Standard Vein filled with PRP); Sham (Control). The left external jugular vein was used as graft in a $10 \mathrm{~mm}$ nervous gap.

Results: In the morphological analysis of all groups, myelinated nerve fibers with evident myelin sheath, neoformation of the epineurium and perineurium, organization of intraneural fascicles and blood vessels were observed. In the morphometry of the distal stump fibers, SVPRP group had the highest means regarding fiber diameter ( $3.63 \pm 0.42 \mu \mathrm{m})$, axon diameter $(2.37 \pm 0.31 \mu \mathrm{m})$ and myelin sheath area $\left(11.70 \pm 0.84 \mu^{2}\right)$. IOVPRP group had the highest means regarding axon area $\left(4.39 \pm 1.16 \mu \mathrm{m}^{2}\right)$ and myelin sheath thickness $(0.80 \pm 0.19$ $\mu \mathrm{m})$. As for values of the fiber area, IOVNF group shows highest means $\left(15.54 \pm 0.67 \mu \mathrm{m}^{2}\right)$, but are still lower than the values of the Sham group.

Conclusion: The graft filled with platelet-rich plasma, with use standard (SVPRP) or inside-out vein (IOVPRP), promoted the improvement in axonal regeneration on sciatic nerve injury.

Key words: Platelet-Rich Plasma. Peripheral Nerves. Sciatic Nerve. Nerve Regeneration. Rats. 


\section{- Introduction}

Traumatic injuries of peripheral nerves are common in clinical practice, accounting for painful neuropathies, decreased motor function and sensory perception, which drastically affect the quality of life of patients and loss of productivity ${ }^{1}$. So, in many cases, the treatment of injuries in peripheral nerve occurs through microsurgical techniques in an attempt to restore impaired nerve function ${ }^{2}$.

In cases of transection, reconstruction with autogenous nerve grafting shows better results in the repair, but becomes unfeasible due to its limitations as greater morbidity at the site of removal of the graft, scarcity of nerve donor sites, structural differences between the donor and receptor nerve, pain caused by neuroma, besides the sensitivity deficit resulting area which was removed ${ }^{3,4}$.

In order to eliminate or minimize the morbidity of the donor site in the repair of damaged peripheral nerve, tubulization, among alternative techniques, shows advantages in setting with extensive nervous commitment, where the use of conventional nerve graft is insufficient for defect to provide the defect filling ${ }^{2}$.

Several types of materials are used as substitutes for nerve autografts, from veins, arteries, muscles, allogenes nerve up to synthetic materials. However, these synthetic materials have not shown to be clinically effective substitutions ${ }^{5}$.

Recently great part of focus in peripheral nerve repair has been concentrating on the applicability of these substitutes associated with cellular therapy. As part of those studies, Platelet-Rich Plasma (PRP) has been widely used to repair damaged nerves, due to the variety of neuro-stimulating substances that accelerate axonal regeneration ${ }^{6,7}$.

Most of the research on reconstructive techniques of peripheral nerves has focused on blend biological materials or artificial as conduits associated with cell therapy. However, for lack of a comparative study between standard and inside-out vein, with or not PRP, this study was performed with the objective of analyzing the effects of inside-out and standard vein grafts, filled or not with PRP, in the regeneration of sciatic nerve lesions in rats.

\section{Methods}

The study was approved by the Ethics Committee on Animal Experimentation of Universidade de Marília.

Animals were previously selected, and comprised 70 Wistar rats (Rattus norvegicus), adults (60 days of age), with an average weight of 195 grams, provided by the Central Animal House of São Paulo State University (UNESP, Botucatu, São Paulo, Brazil) and kept according to laboratory standards.

The animals were randomly divided into five groups: a Sham group $(n=10)$ with no grafts, and four experimental groups ( $n=15$ each): IOVNF group (inside-out vein without filling) got a graft from the left external jugular vein inside-out; the IOVPRP group (inside out vein filled with Platelet Rich Plasma) got a graft from the left external jugular vein with a sample of PRP, the SVNF group (standard vein without filling) got a graft from the jugular vein in standard position, the SVPRP group (standard vein with PRP) got a graft from the jugular vein in standard position with Platelet Rich Plasma.

In the surgical procedures the animals were submitted to a defect with $10-\mathrm{mm}$ gap in the right sciatic nerve and repaired with tubulization by means of a graft taken from the left external jugular vein filled with Platelet Rich Plasma or not. 


\section{Collection and preparation of $P R P$}

$0.8 \mathrm{~mL}$ of peripheral blood was collected from each animal of the groups SVPRP and IOVPRP prior to the operation and processed for PRP preparation. The blood was centrifuged using a Harvest Technologies Smart Prep Centrifuge, with tube with Sodium Citrate $10 \%$ (BD Vacutainer ${ }^{\circ}, \mathrm{NJ}$, USA), 700-800 revolutions/ minute, at $22^{\circ} \mathrm{C}$ for 6 minutes ${ }^{8}$. The blood was separated into three layers: red blood cells at the bottom; acellular plasma at the top; and platelets, called buffy coat, in the middle. After the centrifugation, PRP was pipetted from the middle of the tube. The PRP was mixed with $0.015 \mathrm{~mL}$ of $10 \%$ calcium chloride (activate the growth factors) prior to use.

\section{Surgical procedures}

Animals were first weighed and then anesthetized by intramuscular injection of 50\% tiletamine and $50 \%$ zolazepam at $10 \mathrm{mg} / \mathrm{kg}$ (Telazol ${ }^{\circ}$; Fort Dodge Laboratories, USA).

Aseptic techniques were adopted in all surgical procedures involving the animals. All surgical procedures were performed with the help of a stereo microscope (MC/M9 DF Vasconcellos S/A, São Paulo, Brazil). After anesthesia and trichotomy on the left side of the neck region, a 20-mm longitudinal incision was made in the skin. The jugular vein was isolated and ligature of its confluents was done; then a periodontal probe was introduced and both ends were sectioned (Figure 1A).

In Groups IOVNF and IOVPRP, vein was reversed with the aid of a periodontal probe. The option to use the external jugular vein was due to its larger diameter and the absence of valves, which presented fewer obstacles to axonal regeneration ${ }^{9}$.

This segment of the vein had an average diameter of $1.6 \mathrm{~mm}$ to $2.1 \mathrm{~mm}$ and was $14 \mathrm{~mm}$ in length ${ }^{10}$, and was kept in physiological serum until its placement, as a graft, between the injured nerve stumps. The skin of the donating site was sutured with 4-0 monofilament nylon thread (Ethicon Inc., Somerville, NJ, USA). In the second step, the sciatic nerve (approximately $1.3 \mathrm{~mm}$ in diameter) was exposed (Figure 1B) and sectioned at the left side, and a $10-\mathrm{mm}$ segment was removed.

Processed PRP was introduced into the venous lumen in groups SVPRP and IOVPRP

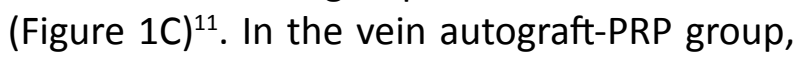
the grafted, inside-out vein was filled with approximately $0.15-0.2 \mathrm{~mL}$ of prepared PRP. PRP was injected into the cavity of vein after anastomosis through the space of stiches. Both the proximal and distal nerve stumps were inserted about 2-3 $\mathrm{mm}$ from the ends of the vein graft $^{5}$.

The epineurium was sutured with 10-0 monofilament nylon suture (Ethicon Inc., Somerville, NJ, USA) ensuring that both the proximal and distal stumps went inside the inside-out and standard vein grafts, about 2 $\mathrm{mm}$ at each end (Figure 1D). Subsequently, the skin was sutured with 4-0 monofilament nylon suture (Ethicon Inc., Somerville, NJ, USA).
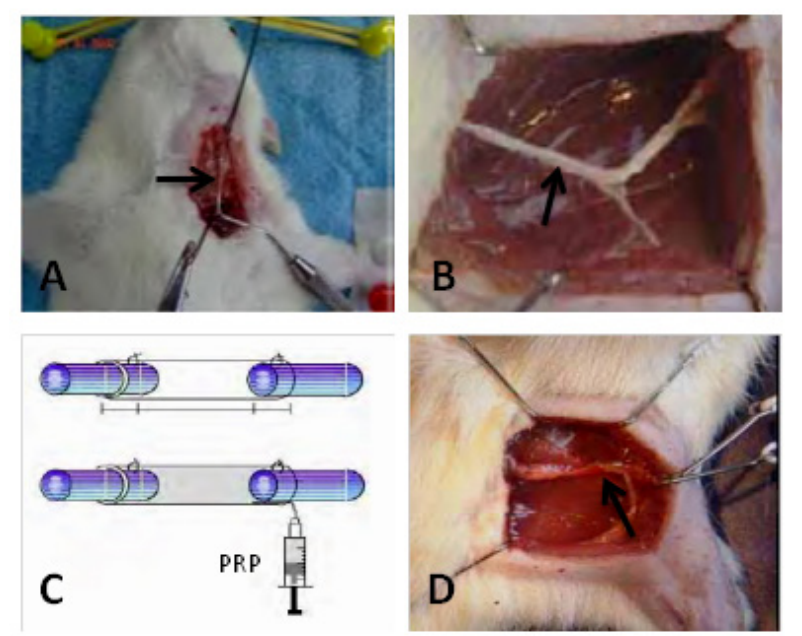

Figure 1 - (A) Removal of the left jugular vein with periodontal probe (black arrow); (B) Exposure of the sciatic nerve (black arrow); (C) Schematic drawing of the filling with PRP; (D) Suture of the standard vein without filling (SVNF group - black arrow). 


\section{Euthanasia and collection of nerve}

Segments Euthanasia of all animals was done after 12 weeks by means of an intraperitoneal injection of a high dose of pentobarbital (Nembutal ${ }^{\bullet}, 30-50 \mathrm{mg} / \mathrm{kg}$, Abbott Laboratory, Quebec, Canada). Afterwards, two fragments were collected, one from the middle third of the vein graft, and the other from the middle third of the distal stump of the right sciatic nerve.

\section{Histological processing of sciatic nerve samples}

Histological processing of samples collected from the graft sites and the distal stumps of the sciatic nerves was performed at the Microscopic and Experimental Anatomy Laboratory of the Institute of Biosciences - UNESP Anatomy Department, Botucatu campus, São Paulo, Brazil. The histological fixative used was modified Karnovsky liquid (Electron Microscopy Sciences ${ }^{\circ}$ Hatfield, Pennsylvania, United States) diluted in sodium cacodylate buffer at $0.1 \mathrm{M}, \mathrm{pH}$ 7.3. After this period of fixation, the sciatic nerves were sectioned crosswise into two segments and left in the same fixative solution that was previously used for a period of one to two hours, and they were post-fixed for two hours in osmium tetroxide at $1 \%$ in sodium cacodylate

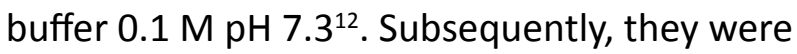
dehydrated in ethanol and propylene oxide and embedded in resin for histological examination.

Cross sections of $0.5 \mu \mathrm{m}$ were obtained with a microtome (RM2265, Leica Biosystem ${ }^{\circ}$, Germany), colored with toluidine blue at $1 \%$ in borax aqueous solution at $1 \%$ and osmium tetroxide for morphological and histomorphometric analysis. The images of histological sections of grafts and distal stumps were captured with 400 times magnification (x40), by means of a video camera coupled to an optical microscope (Axiophot 2 Zeiss KS 300 , Germany) and a computer.

\section{Morphological and histomorphometric analyses}

In the analysis of the sciatic nerves, in the experimental groups, the neuronal morphology and the entire set of structures were observed, namely, the epineurium, perineurium, adipose tissue, intraneural and extraneural blood vessels and myelin sheath.

For the Sham group, assessment of the area and minimum diameter of nerve fibers was performed, as well as the area and minimum diameter of axons, the area and thickness of the myelin sheath; for the other four groups (IOVNF, IOVPRP, SVNF and SVPRP), the assessment was made on the graft and the distal stump. These measures were obtained in four randomly selected fields by using the Image-Pro Plus ${ }^{\mathrm{TM}}$ program, version 6.0 (Media Cybernetics, Rockville, MD, USA). For the histological slides, the assessment was made with SigmaScan Pro version 5.0 (San Jose, CA, USA).

\section{Statistical analysis}

Data obtained were submitted to ANOVA, followed by Scheffé's test. For all analyses, $p<0.05$ values were considered as statistically significant.

\section{Results}

In the histological analyses of the middle third of the grafts and the middle third of the distal stumps, for all groups, there is observed a presence of myelinated nerve fibers with evident sheath, neoformation of the epineurium with external surface covered 
by adipose tissue, perineurium and intraneural organization of fascicles and blood vessels. Histological slides showed no evidence of vein wall used as graft, nor signs of necrosis.

It was possible to observe some blood vessels located near the microfascicles of the SVNF e SVPRP groups. The epineurium and perineurium were clear in the IOVNF e SVPRP groups, and well delimitated in SVNF e SVPRP groups, however, in the SVNF group, they were more fibrous. The fascicles were of different sizes in the IOVNF and SVPRP groups, but in the IOVPRP group they were more compact. The myelin sheath in the distal stump was clear and homogeneous in the IOVNF and SVPRP groups. In the group IOVNF and IOVPRP they appeared more compact (Figures 2 and 3).

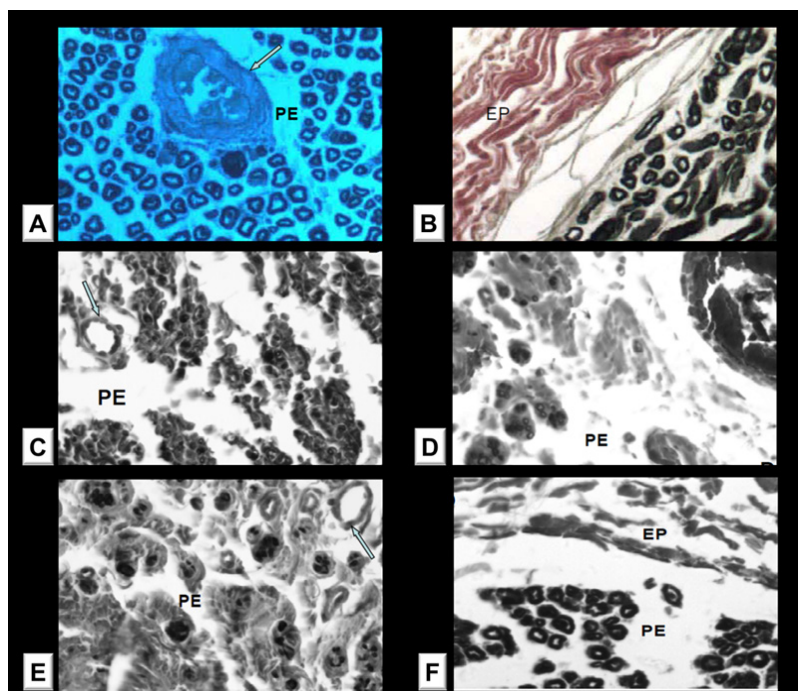

Figure 2 - Graft site (x40): (a) Sham group. Coloration made with osmium tetroxide and counter-staining by toluidine blue; (b) Sham group. Coloration made with osmium tetroxide and counter-staining by eosin; (c) IOVNF group; (d) IOVPRP group; (e) SVNF group; (f) SVPRP group; Perineurium (PE); Epineurium (EP) and blood vessel (arrow).

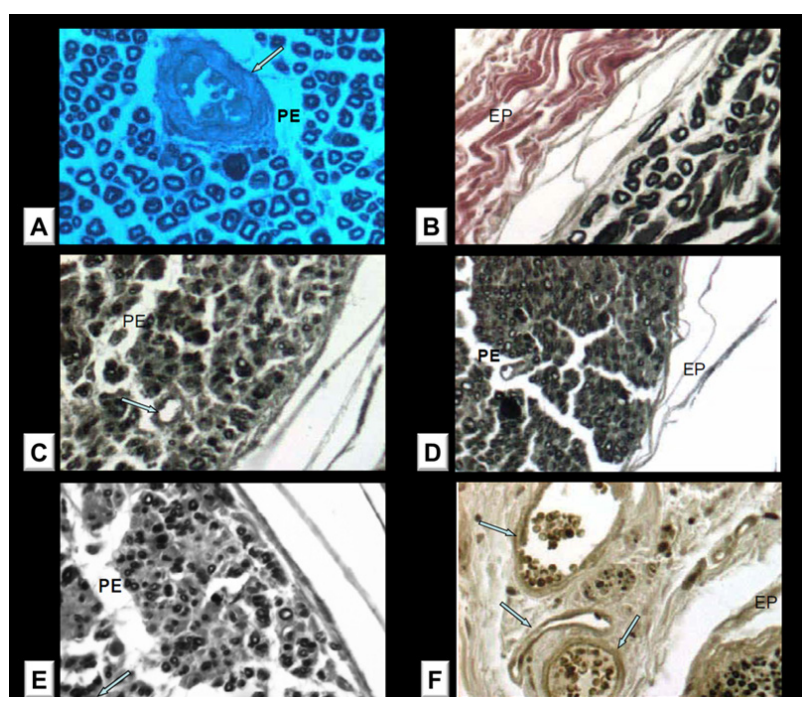

Figure 3 - Distal stump site (x40): (a) Sham group. Coloration made with osmium tetroxide and counter-staining by toluidine blue; (b) Sham group. Coloration made with osmium tetroxide and counter-staining by eosin; (c) IOVNF group; (d) IOVPRP group; (e) SVNF group; (f) SVPRP group; Perineurium (PE); Epineurium (EP) and blood vessel (arrow).

The histomorphometric results for the graft sites region are shown in Table 1. All experimental groups showed significant differences regarding values obtained from the fiber area. The SVPRP group had the highest means, in the analyzed parameters except in the area of the axon (5.52 \pm 0.48$)$, myelin sheath thickness (1.06 \pm 0.37$)$, but are still much smaller compared to the Sham group. However, there is no statistically significant difference between the groups regarding to the values of axon area. The values of myelin sheath thickness between the IOVNF and IOVPRP groups did not present significant difference $(1.44 \pm 0.58$ and $1.26 \pm 0.05)$, respectively $(p<0.05)$. 
Table 1 - Morphometry of nerve fibers on the graft site.

\begin{tabular}{lllllll}
\hline Groups & $\begin{array}{l}\text { Fiber area } \\
\left(\mu \mathrm{m}^{2}\right)\end{array}$ & $\begin{array}{l}\text { Axon area } \\
\left(\mu \mathrm{m}^{2}\right)\end{array}$ & $\begin{array}{l}\text { Fiber } \\
\text { diameter } \\
(\mu \mathrm{m})\end{array}$ & $\begin{array}{l}\text { Axon } \\
\text { diameter } \\
(\mu \mathrm{m})\end{array}$ & $\begin{array}{l}\text { Myelin } \\
\text { sheath area } \\
\left(\mu \mathrm{m}^{2}\right)\end{array}$ & $\begin{array}{l}\text { Myelin } \\
\text { sheath } \\
\text { thickness } \\
(\mu \mathrm{m})\end{array}$ \\
\hline Sham & $42.81 \pm 2.80^{\mathrm{a}}$ & $9.76 \pm 1.75^{\mathrm{a}}$ & $6.24 \pm 0.91^{\mathrm{a}}$ & $2.70 \pm 0.83^{\mathrm{a}}$ & $33.05 \pm 2.21^{\mathrm{a}}$ & $1.77 \pm 0.08^{\mathrm{a}}$ \\
IOVNF & $16.98 \pm 1.01^{\mathrm{b}}$ & $5.01 \pm 1.04^{\mathrm{b}}$ & $5.15 \pm 1.52^{\mathrm{b}}$ & $2.28 \pm 0.77^{\mathrm{b}}$ & $11.97 \pm 1.36^{\mathrm{b}}$ & $1.44 \pm 0.58^{\text {bd }}$ \\
IOVPRP & $22.14 \pm 0.98^{\mathrm{c}}$ & $5.37 \pm 0.72^{\mathrm{b}}$ & $4.45 \pm 0.37^{\mathrm{b}}$ & $1.92 \pm 0.33^{\mathrm{bd}}$ & $16.77 \pm 1.06^{\mathrm{c}}$ & $1.26 \pm 0.05^{\mathrm{bc}}$ \\
SVNF & $15.53 \pm 0.59^{\mathrm{d}}$ & $5.56 \pm 0.65^{\mathrm{b}}$ & $3.55 \pm 1.56^{\mathrm{c}}$ & $1.60 \pm 0.60^{\mathrm{cd}}$ & $12.77 \pm 1.33^{\mathrm{b}}$ & $0.98 \pm 0.56^{\mathrm{ce}}$ \\
SVPRP & $23.48 \pm 0.65^{\mathrm{e}}$ & $5.52 \pm 0.48^{\mathrm{b}}$ & $4.56 \pm 0.81^{\mathrm{b}}$ & $2.45 \pm 0.46^{\mathrm{e}}$ & $18.37 \pm 1.69^{\mathrm{d}}$ & $1.06 \pm 0.37^{\text {de }}$ \\
\hline
\end{tabular}

Groups: Sham (Control Group); IOVNF (Inside-Out Vein with No Filling); IOVPRP (Inside-Out Vein filled with PRP); SVNF (Standard Vein with No Filling); and SVPRP (Standard Vein filled with PRP). Different lower-case letters (a, b, c, d, e) indicate significant difference between groups in each measurement performed (vertical columns) by means of ANOVA, followed by Scheffé's test $(p<0.05)$.

The histomorphometric results for the distal stump region are shown in Table 2. The SVPRP group had the highest means regarding fiber diameter (3.63 \pm 0.42$)$, axon diameter $(2.37 \pm 0.31)$ and myelin sheath area (11.70 \pm 0.84$)$. IOVPRP group had the highest means regarding axon area $(4.39 \pm 1.16)$ and myelin sheath thickness $(0.80 \pm 0.19)$. As for values of the fiber area, the IOVNF group shows highest means (15.54 \pm 0.67$)$, but are still lower than the values of the Sham group.

IOVNF group shows significant difference in the fiber and axon diameter, compared to the SVPRP group ( $p<0.05)$. Differently, there is no significant difference in fiber diameter between IOVPRP and SVPRP groups (3.43 \pm 0.60 and $3.63 \pm 0.42$, respectively).

Table 2 - Morphometry of nerve fibers in the distal stump.

\begin{tabular}{lllllll}
\hline Groups & $\begin{array}{l}\text { Fiber area } \\
\left(\mu \mathrm{m}^{2}\right)\end{array}$ & $\begin{array}{l}\text { Axon area } \\
\left(\mu \mathrm{m}^{2}\right)\end{array}$ & $\begin{array}{l}\text { Fiber } \\
\text { diameter } \\
(\mu \mathrm{m})\end{array}$ & $\begin{array}{l}\text { Axon } \\
\text { diameter } \\
(\mu \mathrm{m})\end{array}$ & $\begin{array}{l}\text { Myelin } \\
\text { sheath area } \\
\left(\mu \mathrm{m}^{2}\right)\end{array}$ & $\begin{array}{l}\text { Myelin sheath } \\
\text { thickness } \\
(\mu \mathrm{m})\end{array}$ \\
\hline Sham & $42.81 \pm 2.80^{\mathrm{a}}$ & $9.76 \pm 1.75^{\mathrm{a}}$ & $6.24 \pm 0.91^{\mathrm{a}}$ & $2.70 \pm 0.83^{\mathrm{a}}$ & $33.05 \pm 2.21^{\mathrm{a}}$ & $1.77 \pm 0.08^{\mathrm{a}}$ \\
IOVNF & $15.54 \pm 0.67^{\mathrm{b}}$ & $3.87 \pm 0.65^{\mathrm{b}}$ & $2.63 \pm 0.45^{\mathrm{b}}$ & $1.35 \pm 0.25^{\mathrm{b}}$ & $11.68 \pm 0.75^{\mathrm{b}}$ & $0.64 \pm 0.13^{\mathrm{b}}$ \\
IOVPRP & $13.28 \pm 1.69^{\mathrm{c}}$ & $4.39 \pm 1.16^{\mathrm{b}}$ & $3.43 \pm 0.60^{\mathrm{cd}}$ & $1.83 \pm 0.68^{\mathrm{ce}}$ & $8.89 \pm 1.36^{\mathrm{c}}$ & $0.80 \pm 0.19^{\mathrm{c}}$ \\
SVNF & $11.39 \pm 1.70^{\mathrm{d}}$ & $3.23 \pm 0.13^{\mathrm{cd}}$ & $2.65 \pm 0.76^{\mathrm{b}}$ & $1.41 \pm 0.52^{\mathrm{be}}$ & $8.16 \pm 1.57^{\mathrm{c}}$ & $0.62 \pm 0.32^{\mathrm{bc}}$ \\
SVPRP & $15.28 \pm 1.03^{\mathrm{b}}$ & $3.58 \pm 0.84^{\text {bd }}$ & $3.63 \pm 0.42^{\mathrm{d}}$ & $2.37 \pm 0.31^{\mathrm{d}}$ & $11.70 \pm 0.84^{\mathrm{b}}$ & $0.63 \pm 0.32^{\mathrm{bc}}$ \\
\hline
\end{tabular}

Groups: Sham (Control Group); IOVNF (Inside-Out Vein with No Filling); IOVPRP (Inside-Out Vein filled with PRP); SVNF (Standard Vein with No Filling); and SVPRP (Standard Vein filled with PRP). Different lower-case letters (a, b, c, d, e) indicate significant difference between groups in each measurement performed (vertical columns) by means of ANOVA, followed by Scheffé's test $(p<0.05)$

\section{- Discussion}

The aim of the present study was to evaluate the influence of platelet-rich plasma
(PRP) in axonal regeneration of peripheral nerve sectioned by means tubulization technique with inside-out and standard vein grafts. 
The choice of the venous tubulization technique associated with cell therapy, In this experiment, demonstrated better histomorphological and histomorphometric results in the vein filled with Platelet Rich Plasma groups (SVPRP e IOVPRP), coinciding with some authors who used other types of filling ${ }^{13-16}$. Thus, it can be suggested that the filling of the vein with biological materials, prevent venous lumen collapse, allowing for better biochemical communication between the nervous stumps, and thus favoring the axonal growth ${ }^{4}$.

In the histomorphological analysis, the experimental groups, vein filled with PRP, (IOVPRP e SVPRP), showed very similar characteristics in the Sham control group. Several clinical and experimental studies justify these findings by the action of the growth factors present in PRP that may have contributed to the better axon regeneration, owing to mitogenic action on Schwann cells and their neurotrophic activity ${ }^{5,17-19}$.

In the histomorphometric analysis, observed were in variables measured (fiber diameter, area and diameter axon) that the groups, IOVPRP e SVPRP, had greatest parameters in distal stump compared with IOVNF and SVNF groups. Such results can be explained by the posttraumatic inhibitory microenvironment and neuropathy generated by PRP through a combinatorial strategy of supplying neurotrophic and neurotrophic factors ${ }^{20}$.

The results of the standard vein with PRP and inside-out vein with PRP, SVPRP and IOVPRP groups respectively, showed equivalence in most of the variables measured at both the graft site and the distal stump. In theory, in cases of peripheral nerve damage such as neuropraxia or axonotmosis, where there was no complete rupture of the nerve, the presence of the neurovascular bundle in contact with the adventitia would provide a favorable microenvironment that could contribute to the repair process ${ }^{16}$. Thus, it can be suggested that laminin and the tunica adventitial, rich in collagen and trophic factors, in direct contact with the axons were not decisive to provide higher histomorphometric results compared to the standard technique ${ }^{21,22}$. Based on these results, the choice of the standard vein technique, evaluated in this study, becomes feasible due to the agility in the surgical process.

Several studies in the literature illustrate basic and pre-clinical evidence on the use of PRP and its relevant products in peripheral nerve regeneration ${ }^{23,24}$. However, we found no evidence of a direct relationship between the growth factors in PRP and the use of the standard vein or inside-out in regeneration nervous.

Failure to of a walking track analysis can be considered a fragility of this study. Still in the search for techniques that shows results next to the nervous grafts and knowing the properties of the platelet aggregates, as future perspectives, it can perform in viability analysis of the Platelet-Rich Fibrin (PRF) as fill material in venous conduits, as well as auxiliary therapies of photobiomodulation ${ }^{25-28}$.

\section{- Conclusion}

Based on the results obtained, it was concluded that the graft filled with PRP, using standard (SVPRP) or inside-out vein (IOVPRP), promoted the improvement in axonal regeneration in sciatic nerve injury.

\section{References}

1 - Grinsell D, Keating CP. Peripheral nerve reconstruction after injury: a review of clinical and experimental therapies. Biomed Res Int. 2014;2014:698256. doi: 10.1155/2014/698256.. 
2 - Sénès FM, Catena $N$, Sénès J. Use of tubulization (nerve conduits) in repairing nerve defects in children. Indian $J$ Orthop. 2015 Sep-Oct;49(5):554-60. doi: 10.4103/0019-5413.164045.

3 - Ichihara S, Inada Y, Nakamura T. Artificial nerve tubes and their application for repair of peripheral nerve injury: an update of current concepts. Injury.2008 Oct;39 Suppl 4:29-39. doi: 10.1016/j.injury.2008.08.029.

4 - Konofaos P, Ver Halen JP. Nerve repair by means of tubulization: past, present, future. J Reconstr Microsurg. 2013 Mar;29(3):14964. doi: 10.1055/s-0032-1333316.

5 - Kim JY, Jeon WJ, Kim DH, Rhyu IJ, Kim YH, Youn I, Park JW. An inside-out vein graft filled with platelet-rich plasma for repair of a short sciatic nerve defect. in rats. Neural Regen Res. 2014 Jul 15;9(14):1351-7. doi: 10.4103/1673-5374.137587.

6 - Cho HH, Jang S, Lee SC, Jeong HS, Park JS, Han JY, Lee KH, Cho YB. Effect of neural-induced mesenchymal stem cells and platelet-rich plasma on facial nerve regeneration in an acute nerve injury model. Laryngoscope. 2010 May;120(5):907-13. doi: 10.1002/ lary.20860.

7 - Kaplan S, Pişkin A, Ayyildiz M, Aktaş A, Köksal $B$, Ulkay MB, Türkmen AP, Bakan F, Geuna S. The effect of melatonin and platelet gel on sciatic nerve repair: an electrophysiological and stereological study. Microsurgery. 2011 May;31(4):306-13. doi: 10.1002/ micr.20876.

8 - Anitua E. Plasma rich in growth factors: preliminary results of use in the preparation of future sites for implants. Int J Oral Maxillofac Implants. 1999 JulAug;14(4):529-35. PMID: 10453668.

9 - Wang KK, Costas PD, Bryan DJ, Jones DS, Seckel BR. Inside-out vein graft promotes improved nerve regeneration in rats. Microsurgery. 1993;14(9):608-18. PMID: 8289647.

10 - Nasir S, Aydin MA, Karahan N, Demiryürek $D$, Sargon M. New microvenous anastomosis model for microsurgical training: external jugular vein. J Reconstr Microsurg. 2006 Nov;22(8):625-30. PMID: 17136675.

11 - Glasby MA, Gschmeissner S, Hitchcock $\mathrm{RJ}$, Huang CL. Regeneration of the sciatic nerve in rats. The effect of muscle basement membrane. J Bone Joint Surg Br. 1986
Nov;68(5):829-33. PMID: 3782256.

12 - Di Scipio F, Raimondo S, Tos P, Geuna S. A simple protocol for paraffin-embedded myelin sheath staining with osmium tetroxide for light microscope observation. Microsc Res Tech. 2008 Jul;71(7):497-502. doi: 10.1002/jemt.20577.

13 - Mohammadi J, Delaviz H, Mohammadi B, Delaviz H, Rad P. Comparison of repair of peripheral nerve transection in predegenerated muscle with and without a vein graft. BMC Neurol. 2016 Nov 22;16(1):237. PMID: 27876000.

14 - Özkan HS, Karataş Silistreli Ö, Ergür B, İrören S. Repairing peripheral nerve defects by vein grafts filled with adipose tissue derived stromal vascular fraction: an experimental study in rats. Ulus Travma Acil Cerrahi Derg. 2016 Jan;22(1):7-11. doi: 10.5505/tjtes.2015.12612.

15 - Roque DD, Pomini KT, Buchaim RL, Buchaim DV , Andreo JC, Roque JS, Rodrigues AC, Rosa- Júnior GM , Moraes LHR, Viterbo F. Inside-out and standard vein grafts, with or without muscle filling, in peripheral nerve repair: a histomorphometric study. BJMMR. 2016;13(1):1-10.

16 - Bueno CRS, Pereira M, Aparecidol FavarettoJúnior, Buchaim RL, Andreo JC, Rodrigues AC, Marco G Rosa-Júnior. Comparative study between standard and inside-out vein graft techniques on sciatic nerve repair of rats. Muscular and functional analysis. Acta Cir Bras. 2017 Apr;32(4):287-96. doi: 10.1590/ s0102-865020170040000005.

17 - Oya T, Zhao YL, Takagawa K, Kawaguchi M, Shirakawa K, Yamauchi T, Sasahara M. Platelet-derived growth factor-b expression induced after rat peripheral nerve injuries. Glia. 2002 Jun;38(4):303-12. PMID: 12007143.

18 - Pereira Lopes FR, Lisboa BC, Frattini F, Almeida FM, Tomaz MA, Matsumoto PK, Langone F, Lora S, Melo PA, Borojevic R, Han SW, Martinez AM. Enhancement of sciatic nerve regeneration after vascular endothelial growth factor (VEGF) gene therapy. Neuropathol Appl Neurobiol. 2011 Oct;37(6):600-12. doi: 10.1111/j.13652990.2011.01159.x.

19 -Glenn TD, Talbot WS. Signals regulating myelination in peripheral nerves and the Schwann cell response to injury. Curr Opin 
Neurobiol. 2013 Dec;23(6):1041-8. doi: 10.1016/j.conb.2013.06.010.

20 - Sánchez M, Garate A, Delgado D, Padilla S. Platelet-rich plasma, an adjuvante biological therapy to assist peripheral nerve repair. Neural Regen Res. 2017 Jan;12(1):47-52. doi: 10.4103/1673-5374.198973.

21 - Tang J, Wang XM, Hu J, Luo E, Qi MC. Autogenous standard versus inside-out vein graft to repair facial nerve in rabbits. Chin J Traumatol. 2008 Apr;11(2):104-9. PMID: 18377714.

22 - Jeon WJ, Kang JW, Park JH, Suh DH, Bae JH, Hong JY, Park JW. Clinical application of inside-out vein grafts for the treatment of sensory nerve segmental defect. Microsurgery. 2011 May;31(4):268-7. doi: 10.1002/micr.20850.

23 - Huang Y, Bornstein MM, Lambrichts I, Yu HY, Politis C, Jacobs R. Platelet-rich plasma for regeneration of neural feedback pathways around dental implants: a concise review and outlook on future possibilities. Int J Oral Sci. 2017 Mar;9(1):1-9. doi: 10.1038/ ijos.2017.1.

24 - Salarinia R, Sadeghnia HR, Alamdari DH, Hoseini SJ, Mafinezhad A, Hoseini M. Platelet rich plasma: Effective treatment for repairing of spinal cord injury in rat. Acta Orthop Traumatol Turc. 2017 May;51(3):254-7. doi: 10.1016/j.aott.2017.02.009.
25 - Buchaim RL, Andreo JC, Barraviera B, Ferreira Junior RS, Buchaim DV, Rosa Junior GM, de Oliveira AL, de Castro Rodrigues A. Effect of low-level laser therapy (LLLT) on peripheral nerve regeneration using fibrin glue derived from snake venom. Injury. 2015 Apr;46(4):655-60. doi: 10.1016/j. injury.2015.01.031.

26 - Buchaim DV, Rodrigues Ade C, Buchaim RL, Barraviera B, Junior RS, Junior GM, Bueno CR, Roque DD, Dias DV, Dare LR, Andreo $J C$. The new heterologous fibrina sealant in combination with low-level laser therapy (LLLT) in the repair of the buccal branch of the facial nerve. Lasers Med Sci. 2016 Jul;31(5):965-72. doi: 10.1007/s10103-0161939-2.

27-RossoMPO, BuchaimDV, JuniorGMR, Andreo JC, Pomini KT, Buchaim RL. Low-Level Laser Therapy (LLLT) improves the repair process of peripheral nerve injuries: a mini review. Int J Neurorehabilitation. 2017;4(2):260. doi: 10.4172/2376-0281.1000260.

28 - Buchaim DV, Andreo JC, Ferreira Junior RS, Barraviera B, Rodrigues AC, Macedo MC, Rosa Junior GM, Shinohara AL, Santos German IJ, Pomini KT, Buchaim RL. Efficacy of laser photobiomodulation on morphological and functional repair of the facial nerve. Photomed Laser Surg. 2017 May 26. doi: 10.1089/pho.2016.4204. [Epub ahead of print]

\section{Correspondence:}

Rogério Leone Buchaim

Universidade de São Paulo, Faculdade de

Odontologia de Bauru

Disciplina de Anatomia, Departamento de Ciências Biológicas

Alameda Dr. Octávio Pinheiro Brisolla, 9-75

17012-901 Bauru - SP Brasil

Tel.: (55 14)3235-8226

rogerio@fob.usp.br

Received: Apr 12, 2017

Review: June 13, 2017

Accepted: July 18, 2017
Conflict of interest: none

Financial source: none 